\title{
BMJ Open Three-decade neurological and neurocognitive follow-up of HIV-1-infected patients on best-available antiretroviral therapy in Finland
}

\author{
T Heikinheimo, ${ }^{1}$ E Poutiainen, ${ }^{1,2}$ O Salonen, ${ }^{3}$ I Elovaara, ${ }^{4}$ M Ristola ${ }^{5}$
}

To cite: Heikinheimo T, Poutiainen E, Salonen 0 , et al. Three-decade neurological and neurocognitive follow-up of HIV-1-infected patients on best-available antiretroviral therapy in Finland. BMJ Open 2015;5:e007986

doi:10.1136/bmjopen-2015007986

- Prepublication history for this paper is available online. To view these files please visit the journal online (http://dx.doi.org/10.1136/ bmjopen-2015-007986).

Received 16 February 2015 Revised 19 September 2015 Accepted 30 September 2015

\section{CrossMark}

For numbered affiliations see end of article.

\section{Correspondence to}

Dr T Heikinheimo;

terttu.heikinheimo-connell@ hus.fi

\section{ABSTRACT}

Objectives: Is it possible to live without neurocognitive or neurological symptoms after being infected with HIV for a very long time? These study patients with decades-long HIV infection in Finland were observed in this follow-up study during three time periods: 1986-1990, in 1997 and in 2013.

Setting: Patients from greater Helsinki area were selected from outpatient's unit of infectious diseases. Participants: The study included 80 HIV patients. Patients with heavy alcohol consumption, central nervous system disorder or psychiatric disease were excluded.

Primary and secondary outcome measures: The patients underwent neurological and neuropsychological examinations, MRI of the brain and laboratory tests, including blood CD4 cells and plasma HIV-1 RNA. Neuropsychological examination included several measures: subtests of Wechsler Adult Intelligence Scale, Wechsler Memory Scale-Revised, list learning, Stroop and Trail-Making-B test. The Beck Depression Inventory and Fatigue Severity Scale were also carried out. The obtained data from the three time periods were compared with each other.

Results: Owing to high mortality among the original 80 patients, eventually, 17 participated in all three examinations performed between 1986 and 2013. The time from the HIV diagnosis was 27 (23-30) years. Blood CD4 cells at the diagnosis were 610 (29-870) cells $/ \mathrm{mm}^{3}$, and the nadir CD4 $168(4-408)$ cells $/ \mathrm{mm}^{3}$. The time on combined antiretroviral treatment was 13 (5-17) years. 9 patients suffered from fatigue, 5 had polyneuropathy and 3 had lacunar cerebral infarcts. There was a subtle increase of brain atrophy in 2 patients. Mild depressive symptoms were common. The neuropsychological follow-up showed typical agerelated cognitive changes. No HIV-associated dementia features were detected.

Conclusions: Polyneuropathy, fatigue and mild depression were common, but more severe neurological abnormalities were absent. These long-term surviving HIV-seropositive patients, while on best-available treatment, showed no evidence of HIV-associated

\section{Strengths and limitations of this study}

- The study was a very long-term, meticulous follow-up of HIV-infected patients.

- The study evaluated almost half of the Finnish HIV population during 1986-1990.

- A systematic neuropsychological and neurological, neuroimaging and HIV infection assessment is included.

- The study sample is small.

- Survival bias.

neurocognitive disorder in neuropsychological and neuroradiological evaluations.

\section{INTRODUCTION}

HIV has been challenging mankind for more than 30 years. The virus crosses the bloodbrain barrier (BBB) and enters the central nervous system (CNS) at an early stage of the infection-and never leaves it. Without treatment, HIV gradually causes a variety of neurological complications including HIV-associated neurocognitive disorder (HAND). This can vary from a clinically asymptomatic or mild neurocognitive disorder to severe HIV-associated dementia (HAD). With the development of combined antiretroviral therapy (cART), patients with good adherence can live a long symptom-free life, and HAD has become rare. ${ }^{1}$ However, cART does not eliminate the virus, and it is claimed that a substantial portion of patients still develop neurocognitive impairments. ${ }^{2-5}$ A low level of cell-to-cell viral replication also occurs during the most successful cART regimens. ${ }^{67}$ Even during effective cART there is a latent reservoir of blood CD4 cells carrying the HIV genome, which is competent for replication. ${ }^{8}{ }^{9}$ Low nadir CD4 seems to predict, at 
least partially, reversible HAND. ${ }^{2}$ Very long-term follow-up studies on the evolution of neurocognitive function among HIV-infected patients are lacking. To the best of our knowledge, this is the first study describing a group of patients followed up to as many as 30 years.

Public healthcare provides HIV treatment in Finland. In the Helsinki area, the infectious disease unit at Aurora Hospital has provided medical treatment for HIV infection since $1983 .{ }^{10}$ The first antiretroviral agent, zidovudine, became available at Aurora Hospital in 1987. A cohort study was started in 1986, lasting 5 years, to examine the CNS symptoms associated with HIV infection. ${ }^{11}$ The HIV-infected patients were then reinvestigated in $1997 .^{12}$ For this study, we re-invited the patients in 2013, to obtain a longitudinal evaluation of their neurocognition, and to examine the neurological and neuroimaging findings of this group of people who became infected with HIV-1 more than 25 years ago, and who have been treated with optimal therapy. In Finland, antiviral HIV medication is free for patients through the Finnish communicable disease legislation.

\section{METHODS}

\section{Centre and patients}

This is an observational follow-up study of HIV-infected patients who were first enrolled in a neurological and neuropsychological examination during 1986-1990. ${ }^{13} 14$ HIV infection and AIDS are reportable diseases in Finland. The first patient with an HIV infection was diagnosed in $1983 .{ }^{10}$ The infectious disease unit at Aurora Hospital in Helsinki takes care of HIV-infected individuals within the greater Helsinki area. The hospital managed a total of 98 HIV-infected patients in 1986. The number of patients increased every year to 248 by the year 1991. Around half of these patients $(n=106)$ were first evaluated for this study during 1986-1990. The exclusion criteria were: history of CNS disease or present HIV-related CNS disease (not HAD), severe dementia, marked learning disability, prominent alcohol consumption (scale 4, see below) and refusal to participation. Thus, 85 patients participated in the initial study. ${ }^{13} 15$ Later, a further five patients with previously diagnosed psychiatric problems were excluded. Thus the study cohort available for the follow-up totalled 80 persons. We included those patients who were re-invited and who agreed to participate in all three study interventions in $1986-1990,{ }^{11} 1997^{12}$ and 2013 , in this analysis.

\section{Study interventions}

During all three examination periods, detailed medical history was taken together with information on patients' educational background, profession and occupation. From each patient's medical records and previous research records, the following data were recorded: dates of acquisition and diagnosis of HIV infection, history of ART, and the date of initiation of cART and possible interruptions of the therapy. Virologically suppressive therapy was defined as having most plasma HIV viral loads below the limit of detection before the year 2000 and below 50 copies $/ \mathrm{mL}$ thereafter. Blood CD4 cells $\left(\right.$ cells $\left./ \mathrm{mm}^{3}\right)$ within the year of diagnosis and nadir CD4 (the lowest blood CD4 cells value measured since patient's HIV diagnosis), the date of plasma HIV-1 RNA level being below 400 copies and below 50 copies, and any AIDS events, were recorded. Patients were further divided into two groups depending on whether they had used cART for more than 10 years continuously versus patients with $<10$ years of cART use, or treatment interruptions. Patients were also divided into those with low nadir CD4 $\left(<200\right.$ cells $\left./ \mathrm{mm}^{3}\right)$ and those with higher nadir $\mathrm{CD} 4$ values, and compared.

The diagnosis of other conditions was recorded from the medical records and using information from the patient: medication or diet used for diabetes mellitus, hypertension (treated, or a history of hypertension as systolic blood pressure $\geq 140 \mathrm{~mm} \mathrm{Hg}$ or diastolic blood pressure $\geq 90 \mathrm{~mm} \mathrm{Hg}$, or both), hypercholesterolaemia (treated or total cholesterol level $\geq 5.0 \mathrm{mmol} / \mathrm{L}$, low-density lipoprotein (LDL) level $\geq 3.0 \mathrm{mmol} / \mathrm{L}$, or high-density lipoprotein (HDL) level $<1.0 \mathrm{mmol} / \mathrm{L}$ ) and cardiovascular disease (prior diagnosis of coronary heart disease or myocardial infarction). Diagnosis of nephropathy or signs of protein in urine were recorded. Any history of depression or bipolar disorder, and diagnosis of epilepsy or dementia, were ascertained. Patients were also questioned about their smoking habits, and whether they used any illegitimate drugs. Alcohol consumption was estimated (scale 0-4) in the first and last evaluations. ${ }^{15}$ In the scale, $0=$ infrequent use $(0-100 \mathrm{~g}$ alcohol per week), 1=social drinker $(101-250 \mathrm{~g})$, 2=moderate user $(251-350 \mathrm{~g}), 3=$ heavy drinker $(351-500 \mathrm{~g})$ and $4=$ alcohol abuser $(>500 \mathrm{~g})$. The body mass index was calculated for all patients, to estimate their nutritional status (underweight body mass index (BMI) $\left.\leq 18.5 \mathrm{~kg} / \mathrm{m}^{2}\right)$ and obesity $\left(\mathrm{BMI} \geq 30 \mathrm{~kg} / \mathrm{m}^{2}\right)$.

\section{Neurological investigations}

In 2013, all the participants completed a fatigue severity scale (FSS) form translated into Finnish, to determine the level of fatigue patients were experiencing. ${ }^{16}$ The FSS has nine statements with a score range 1-7. The patient accords a value based on how well the statement reflects his condition during the previous week. A total score $\geq 36(\max 63)$ in the FSS suggests the patient is suffering from fatigue. ${ }^{16}$

In the year 2013 assessment, the diagnosis of polyneuropathy or treatment of neuropathic pain was recorded.

Each participant underwent a neurological evaluation performed by a neurologist in all three time periods. In 2013, we used a neurostatus scoring system and the expanded disability scale status (EDSS). ${ }^{17}$ The neurostatus is divided into the domains of visual, brainstem, pyramidal, cerebellar, sensory and bowel/bladder. We excluded the cerebral domain, because we 
undertook neuropsychological investigations with more detailed information. Each domain gives the patient a functional system score (FS) where $0-1=$ no symptoms, signs only; $2-3=$ mild symptoms and signs; $3=$ moderate symptoms and signs; $4-6=$ severe symptoms and signs. The domains are used to determine patients' EDSS together with patient's ability to walk (ambulatory). Both the neurostatus and EDSS are used widely to estimate the functional disability of patients with multiple sclerosis. For this study, they were adapted with the purpose of standardising the neurological status and making the clinical neurological examination easier to analyse quantitatively.

\section{Neuropsychological investigation}

The neuropsychological examination included measures of memory: the Logical Memory I of the Wechsler Memory Scale-Revised (Wechsler's memory scale (WMS)-R) ${ }^{18}$ and a list learning task. ${ }^{19}$ The reasoning was assessed using Similarities and Block Design subtests of the Wechsler Adult Intelligence Scale (WAIS). ${ }^{20}$ The executive functions were assessed with the Trail Making $\mathrm{B}^{21}$ and the Interference subtask of the Stroop colour word test. ${ }^{22}$ The speed of performance was measured with the Digit Symbol subtest of the WAIS and a naming subtest of the Stroop colour word test. Depression was evaluated with a short form of the Beck Depression Inventory (BDI). ${ }^{23}$ All participants were investigated with the same neuropsychological tests in all three study periods.

\section{Neuroradiological investigation}

MRI was performed on 16 patients both in 1997 and 2013. The first brain MRI was performed using a $1.5 \mathrm{~T}$ unit (Siemens, Vision). The MRI protocol included conventional T2, fluid-attenuated inversion recovery, T2 coronal and T1 multiplanar reconstruction (MPR) sagittal images. The second imaging, in 2013, was performed using a $3 \mathrm{~T}$ unit (Philips, Achieva). The MRI protocol also included $\mathrm{T} 2^{*}$, susceptibility weighted imaging (SWI) and diffusion weighted imaging (DWI) axial sequences.

All brain abnormalities including infarcts and bleedings were recorded. White matter hyperintensities (WMHIs) were classified as periventricular WMHIs or deep WMHIs, and graded 0 through 3 . The severity of white matter lesions (WMLs) was rated with the Fazekas scale. ${ }^{24}$ The bicaudate ratios and the width on the third ventricle were measured to estimate brain atrophy.

\section{Laboratory investigations}

Apart from the HIV laboratory work up aforementioned, the following laboratory assessments were made: a complete blood count, liver function (aspartate aminotransferase, alanine aminotransferase, alkaline phosphatase, total bilirubin), kidney function (creatinine, protein in urine), plasma glucose and lipids (total cholesterol, high HDL, LDL and triglycerides), viral hepatitis serology (hepatitis B antigens (HBsAg, HBcAb), hepatitis C antigen (HCVAb), syphilis serology (treponema pallidum haemagglutination and cardiolipin antigen (Venereal Disease Research Laboratory) tests).

A current cerebrospinal fluid (CSF) sample was available for routine analysis from nine patients.

\section{Statistics}

Statistical analyses were computed using IBM statistics software SPSS V.22.00. Neuropsychological parameters were analysed with multivariate analyses of variance (Manovas) controlling the effect of age in all analyses. In the analysis of other parameters, simple parametric and non-parametric tests along with simple descriptive statistics, were used, as appropriate.

All patients gave their written informed consent to participate in the study.

\section{RESULTS}

After exclusions, the original study group consisted of 80 patients during the period 1986-1990. By the 1997 evaluation, 47 patients had passed away, 7 had been lost to follow-up and 3 patients refused the follow-up evaluation; consequently, 23 patients were evaluated in 1997. Between 1997 and the current evaluation, a further five patients had passed away, two from AIDS-related complications after 1997, and three from non-AIDS-related causes four or more years after 1997. For the latest evaluation, we were able to contact 18 HIV-infected patients to participate in the neurological, neuropsychological, radiological and laboratory work up. The patients were all men. They had a sexually acquired HIV infection, 16 through homosexual or bisexual contact and two through heterosexual contacts. All 18 patients gave their consent to participate in the study. One was too ill to participate in extended investigations and was only visited by the neurologists. His EDSS was 9.0. During the intervention in 2013, he died. No signs of HIV-associated brain damage were observed in post mortem autopsy. The results of the remaining 17 patients are reported here.

The demographic and clinical characteristics are presented in table 1 . Of the 17 patients, $11(65 \%)$ had low nadir CD4 of $<200$ cells $/ \mathrm{mm}^{3}$, and $3(18 \%)$ had had AIDS events (one patient with oesophageal candida, one with pneumocystis pneumonia, and one with Kaposi's sarcoma and pneumocystis pneumonia. The patient with two AIDS illnesses had convulsions twice while receiving treatment for pneumocystis pneumonia). There were no elite controllers of HIV-1 viraemia among the patients, whose median of the maximal HIV-1 viral load in plasma was 145000 copies/mL (range 10 900-9 360000 copies $/ \mathrm{mL}$ ). The median year of first starting ART was 1992 (range 1989-2002). Nine patients had undergone continuously virologically suppressive ART for 10 years or longer. The remaining eight patients had had interruptions of suppressive ART or had taken continuously 
Table 1 Demographic and clinical characteristics of the study population

\begin{tabular}{lll}
\hline Characteristic (unit) & Median & Range \\
\hline Age (years) & 57.0 & $46-75$ \\
Education (years) & 12.0 & $9-23$ \\
HIV infection* (years) $\mathrm{n}=16$ & 28 & $23-31$ \\
HIV diagnosis† (years) & 27 & $23-30$ \\
CD4 at diagnosis $\ddagger$ (cells $/ \mathrm{mm}^{3}$ ) $\mathrm{n}=15$ & 610 & $29-870$ \\
nadir CD4 (cells $/ \mathrm{mm}^{3}$ ) & 168 & $4-408$ \\
ARV (years) & 19 & $9-24$ \\
cART (years) & 13 & $5-17$ \\
BMI (kg/m ${ }^{2}$ ) & 23.4 & $17.5-34.3$ \\
EDSS & 2.0 & $1.0-4.0$ \\
FSS & 32 & $9-63$ \\
\hline
\end{tabular}

The number of patients $(n)$ is 17 unless mentioned otherwise. *Patients' own estimations about time from HIV infection. †Time from HIV diagnosis.

$\ddagger$ The first blood CD4 cells, within a year of the diagnosis. ARV, use of any antiretroviral therapy; BMI, body mass index; cART, antiretroviral therapy consisting of at least 3 agents; EDSS, expanded disability scale status; FSS, fatigue status scale.

suppressive ART for $<10$ years. The current antiretroviral combinations are shown in table 2.

Depression was diagnosed and treated in 4 (24\%) patients. In the results of BDI between the three study time periods no significant changes appeared: BDI mean scores were 4.65, 5.53 and 5.00, respectively (Friedman, $\chi^{2}=0.5, \mathrm{p}=0.779$ ) indicating mild depressive symptoms. The BDI result did not vary between the groups of low nadir CD4 or patients with cART for more than 10 years. Hypertension was medicated and treated in 5 (29\%) patients. Diabetes was diagnosed in two patients. Nephropathy was diagnosed in two patients, one caused by diabetes and the other by prostatic hyperplasia, while two other patients had protein in urine. Dyslipidaemia was diagnosed in $11(65 \%)$ patients. One patient was underweight (BMI $17.5 \mathrm{~kg} / \mathrm{m}^{2}$ ) and one

\begin{tabular}{|c|c|c|}
\hline cART regime & $\begin{array}{l}\text { Number of } \\
\text { patients }\end{array}$ & Remarks \\
\hline 2NRTI+boosted PI & 7 & \\
\hline 2NRTI+NNRTI & 3 & \\
\hline 2NRTI+INSTI & 1 & \\
\hline $\begin{array}{l}\text { 1NRTI+boosted PI } \\
+ \text { INSTI }\end{array}$ & 1 & Intolerance to NRTIs \\
\hline $\begin{array}{l}\text { 1NRTI+boosted PI } \\
+\mathrm{NNRTI}\end{array}$ & 1 & 1 class ART resistance \\
\hline $\begin{array}{l}\text { NNRTI+boosted PI } \\
+ \text { INSTI }\end{array}$ & 2 & $\begin{array}{l}2 \text { class ART resistance } \\
\text { in both patients }\end{array}$ \\
\hline $\begin{array}{l}\text { 2NRTI+boosted PI } \\
+\mathrm{NNRTI+INSTI}\end{array}$ & 2 & $\begin{array}{l}3 \text { class ART resistance } \\
\text { in both patients }\end{array}$ \\
\hline $\begin{array}{l}\text { 2NRTI, two nucleosid } \\
\text { antiretroviral therapy; I } \\
\text { NNRTI, non-NRTI; PI, }\end{array}$ & $\begin{array}{l}\text { reverse transc } \\
\text { JSTI, integrase } \\
\text { protease inhibit }\end{array}$ & $\begin{array}{l}\text { ptase inhibitors; ART, } \\
\text { strand transfer inhibitor; } \\
\text { r. }\end{array}$ \\
\hline
\end{tabular}

obese (BMI $34.3 \mathrm{~kg} / \mathrm{m}^{2}$ ). Alcohol consumption had been moderate and was reduced significantly between the first and last examination (mean score \pm SD: 0.82 \pm .0 .64 vs $0.35 \pm 0.79$, Wilcoxon, $\mathrm{Z}=-2.3$, $\mathrm{p}=0.021$ ).

Tobacco smoking was noted in $7(41 \%)$ patients. One patient admitted to occasionally using marihuana. None of the patients used intravenous or other illegitimate drugs.

Four of the patients had a diagnosis of neuropathy. On clinical neurological examination, an additional patient had signs of neuropathy (Sensory FS 3.0-4.0). Four of five patients with neuropathy had been treated with deoxynucleosides, four with stavudine from 3 to 10 years and 3 with didanosine from 3 to 4.5 years. Only one patient with neuropathy had not been treated with deoxynucleosides. Altogether, six patients had EDSS between 3.0 and 4.0 (mean=3.4), indicating moderate disability. In five, this was due to neuropathy. One patient had mild extrapyramidal findings and bladder dysfunction, which increased his EDSS. None of the patients had prominent loss of vision, cerebellar ataxia, marked pyramidal symptoms or other clear signs of CNS abnormalities. They were all fully ambulatory. Most of the patients (16) had intact sensation of smell.

The neuropsychological examination showed a mild decline in raw scores, particularly between the second and last examination, but no significant changes were found when age was controlled for in statistical analyses (repeated measures Mancova) (table 3). No effect on cognition was traced on patients during the follow-up whether they were on cART for at least 10 years continuously, for $<10$ years, had an interruption of cART, or low nadir CD4.

The neuroradiological follow-up showed only a minimal age-related increase in atrophic changes. The mean bicaudate ratio was 0.12 in 1997 and 0.13 in 2013, and the mean width of the third ventricle was 0.57 and $0.68 \mathrm{~cm}$, respectively. Two of the patients showed a slightly more prominent increase in atrophy. Four patients had new WMHIs. Three of the patients had new lacunar infarcts, one of which had already been seen in 1997. One of the three patients also had microhaemorrhages not seen in 1997. One of these patents with stroke was the eldest ( 75 years) of our study group and had some decline in neuropsychological performance. However, the other patients with mild brain atrophy or stroke seen in the MRI had no detectable decline in cognitive performance.

A CSF sample was taken from nine patients in 2013. HIV-1 in CSF was below 20 copies/mL in eight patients. The amplification test failed technically on one sample. About half of the patients had elevated protein or immunoglobulin in CSF (table 4). The leucocyte count and immunoglobulin-albumin ratio were within normal range in most patients studied (table 4).

Five patients had positive $\mathrm{HBcAb}$, indicating an earlier hepatitis B infection. None, however, were HBsAg positive; hence none of the patients were chronically 
Table 3 Cognitive functioning of the $17 \mathrm{HIV}$-infected patients at three follow-up examinations

\begin{tabular}{|c|c|c|c|c|c|c|}
\hline \multirow{2}{*}{$\begin{array}{l}\text { Year of examination } \\
\text { Follow-up time/years }\end{array}$} & \multirow{2}{*}{$\begin{array}{l}1986-1990 \\
0 \\
\text { Mean (SD)† }\end{array}$} & \multirow{2}{*}{$\begin{array}{l}1997 \\
7-11 \\
\text { Mean (SD) }\end{array}$} & \multirow{2}{*}{$\begin{array}{l}2013 \\
23-27 \\
\text { Mean (SD) }\end{array}$} & \multicolumn{2}{|c|}{ Manova/Anova* } & \multirow{2}{*}{$\begin{array}{l}\text { Effect size } \\
\eta^{2}\end{array}$} \\
\hline & & & & $\bar{F}$ & p Value & \\
\hline \multicolumn{7}{|l|}{ Cognitive function } \\
\hline Memory & & & & 1.920 & 0.172 & 0.390 \\
\hline WMS logical memory & $11.9(2.1)$ & $13.8(2.5)$ & $10.0(2.6)$ & - & - & - \\
\hline List learning & $57.9(6.2)$ & $61.9(5.4)$ & $57.3(7.4)$ & - & - & - \\
\hline Reasoning & & & & 0.895 & 0.496 & 0.230 \\
\hline WAIS similarities & $21.9(1.7)$ & $21.3(1.8)$ & $20.9(2.0)$ & - & - & - \\
\hline WAIS block design & $40.9(6.5)$ & $41.5(5.3)$ & $37.9(6.1)$ & - & - & - \\
\hline Executive function & & & & 0.330 & 0.953 & 0.099 \\
\hline Trail-making B & $85.3(21.5)$ & $99.4(29.8)$ & $105.9(27.2)$ & - & - & - \\
\hline Stroop interference test (time) & $104.2(24.8)$ & $99.2(22.6)$ & $115.5(34.8)$ & - & - & - \\
\hline Speed of performance & & & & 1.221 & 0.353 & 0.289 \\
\hline WAIS digit symbol & $59.3(11.0)$ & $55.4(16.8)$ & $48.9(12.7)$ & - & - & - \\
\hline Stroop naming (time) & $55.4(11.6)$ & $57.0(11.4)$ & $67.4(15.7)$ & - & - & - \\
\hline
\end{tabular}

infected with hepatitis B. One patient had a positive syphilis serology with history, and a serological follow-up of an adequate treatment of syphilis. All patients were HCVAb negative.

\section{DISCUSSION}

This study shows, for the first time, that Finnish HIV-1-infected patients who receive adequate anti-HIV therapy may preserve their neurological and neurocognitive function well despite of a history of HIV infection of up to 30 years.

All cART-medication regimes are reducing the risk of the severest forms of HAND. Nevertheless, milder forms have been reported as becoming more common. ${ }^{25} 26$ HIV is transported from the periphery through the BBB in the CNS with both monocytes and CD4 cells. ${ }^{27}{ }^{28}$ In the CNS, the monocytes transfer HIV into macrophages and microglial cells, both of which can produce HIV virions. HIV infection may either be haematogenous or 'autonomous', when viral replication takes place in the CNS, or a mixture of both. ${ }^{27}$ Astrocytes also become infected with HIV, but HIV does not replicate in astrocytes. The infected macrophages and microglial cells elicit an inflammatory reaction, which leads to recruitment of more infected immune cells in the brain. ${ }^{28}$

Table 4 Cerebrospinal fluid of nine patients in 2013

\begin{tabular}{llll}
\hline & Median & Range & $\begin{array}{l}\text { Over upper } \\
\text { limit of normal }\end{array}$ \\
\hline Protein, $\mathrm{mg} / \mathrm{L}$ & 451 & $268-675$ & $5 / 9$ \\
Leucocytes & 1 & $0-4$ & $1 / 9$ \\
Immunoglobulin & 31 & $10-82$ & $4 / 9$ \\
Ig index & 0.60 & $0.55-0.70$ & $4 / 9$ \\
Ig/Alb index & 0.16 & $0.09-0.22$ & $1 / 9$ \\
\hline
\end{tabular}

Further astrocytes contribute to the damage of the brain by producing neurotoxic factors, such as glutamate. ${ }^{26}$ The only known therapy reducing CNS damage by HIV is ART. Even a monotherapy with zidovudine decreases the amount of inflammatory reaction in the $\mathrm{CSF}^{29}$ The modern cART regimens inhibit the replication of HIV almost completely in the periphery. These regimens have been shown to reduce the HIV load to an undetectable level in the CNS in most patients. ${ }^{30}$ The inflammation markers in the CSF may persist at an elevated level even after 4 years of virologically successful cART. ${ }^{31}$ Our results indicate that cognitive function can be preserved in HIV-infected patients for a couple of decades, despite the probable inflammatory activity in the CNS.

Some HIV-infected patients have been described as having a viral escape of HIV in the CNS in spite of successful cART in the periphery. ${ }^{32}$ The phenomenon is fairly rare, affecting a minority of patients receiving successful cART. Taking into account the laboratory investigations, clinical examinations and brain MRI performed, it appears our cohort did not include such patients. The factors contributing to the good cognitive state in our patients probably include long-term ART, which, on average, had been 19 years, of which, on average, 13 years had been on cART. Second, the lack of drug abuse, which is perhaps synergistic with HIV to cause HAND. The CHARTER study recruited 1555 HIV-infected patients across the USA and found that $52 \%$ had at least mild neuropsychological impairment. ${ }^{2}$ In that study sample, about one-third (28\%) were using some recreational drug. Third, the good neurocognitive outcome is caused most likely by biological variation in our patients' properties to resist HIV infection, and their willingness to start ART. Fourth, lack of hepatitis C infection may contribute to the good neurocognitive outcome of our patients. ${ }^{33} 34$ 
The only significant neurological impairment detected in our study population was peripheral neuropathy. Apart from one patient with extrapyramidal signs, no signs of other CNS impairment were found on clinical examination. The earlier ART probably contributed to the development of neuropathy, because many patients had used deoxynucleoside analogues, which are known to cause toxic neuropathy, as a part of their ART.

A great proportion of our patients had diseases that constitute risks for cerebrovascular diseases. However, the only risk factor that was significantly higher than in the general population of Finland, was, expectedly, the prevalence of hypercholesterolaemia. This is a well-known side effect of cART, especially the group of protease inhibitors. ${ }^{35}$ Diabetes, hypertension and hypercholesterolaemia were treated appropriately, which also decreased the risks for neurological and neurocognitive defects.

Although the neuropsychological raw scores declined, especially between the second and last examination, no significant differences were found when the effect of age was controlled for. Thus, the decline may be explained by the normal ageing effects, as the follow-up period was almost 30 years, with the patients being, on average, 57 years of age at the time of the last examination.

In the MRI, the signs of silent strokes support the research, which shows an increase of the incidence of stroke in the ageing HIV population. ${ }^{37}{ }^{38}$ Only two of our patients had developed brain tissue atrophy that was more significant than in generally healthy ageing men (annually $0.1-0.3 \%) .3940$

The limitations of the study include the survival benefit and small sample size. It may well be that our population of survivors from the era when anti-HIV medication was not available or did not give long-term suppression of HIV-1 replication represent a subgroup of HIV-infected patients who tolerate the infection better than men on average. On the other hand, the recruited study group represents almost a half of HIV-infected patients treated in Aurora Hospital during the 1980s.

In conclusion our results give credence to the view that HIV-1-infected patients may well preserve their neurocognitive function when cART is started in time and delivered well, and when other conditions that could threaten the brain are treated appropriately. Apart from polyneuropathy, no significant neurological or neuropsychological trend of impairment was found in our study group. It is possible that the prevalence of neurocognitive impairment in the CHARTER study may not apply to all HIV-1-infected patients.

\footnotetext{
Author affiliations

${ }^{1}$ Department of Neurology, Helsinki University Central Hospital, Helsinki, Finland

${ }^{2}$ Rehabilitation Foundation, Helsinki, Finland

${ }^{3}$ Department of Radiology, Helsinki University Central Hospital, Helsinki, Finland

${ }^{4}$ Neuroimmunology Unit, Medical School, University of Tampere, Tampere, Finland
}

${ }^{5}$ Department of Infectious Diseases at Aurora Hospital, Helsinki University Central Hospital, Helsinki, Finland

Acknowledgements The authors thank Ms Outi Debnam, RN, for practical assistance in conducting this study. They also thank Tim Connell for proofreading the article.

Contributors TH drafted the first versions of the article. EP and IE collected the original data and the evaluations during 1986-1990 and 1997. EP and TH produced the statistical data, and OS analysed the MRIs from 1997 and 2013. MR evaluated the HIV infection in 1997 and 2013, and organised the evaluation of the cohort in 2013. EP carried out the neuropsychological assessment and TH performed the neurological assessment.

Funding This work was supported by an unrestricted research grant for the intervention in 2013 through the Clinical Research Institute of HUCH by AbbVie. TH received support from Helsinki University Hospital research funds, Maire Taponen Foundation and Orion research funds.

Competing interests $\mathrm{TH}$ received travel expenses from AbbVie, Bayer and Orion. EP received travel expenses and consultations from AbbVie. MR received Honoraria, consultations or travel expenses from Abbvie, BMS, Gilead, GSK, Janssen and Merck.

Ethics approval The Medical Ethical committee of the Hospital District of Helsinki and Uusimaa.

Provenance and peer review Not commissioned; externally peer reviewed.

Data sharing statement Additional data is available by emailing: Terttu. heikinheimo-connell@hus.fi

Open Access This is an Open Access article distributed in accordance with the Creative Commons Attribution Non Commercial (CC BY-NC 4.0) license, which permits others to distribute, remix, adapt, build upon this work noncommercially, and license their derivative works on different terms, provided the original work is properly cited and the use is non-commercial. See: http:// creativecommons.org/licenses/by-nc/4.0/

\section{REFERENCES}

1. d'Arminio Monforte A, Cinque P, Mocroft A, et al. Changing incidence of central nervous system diseases in the EuroSIDA cohort. Ann Neurol 2004;55:320-8.

2. Heaton RK, Clifford DB, Franklin DR Jr, et al. HIV-associated neurocognitive disorders persist in the era of potent antiretroviral therapy: CHARTER Study. Neurology 2010;75:2087-96.

3. Heaton RK, Franklin DR, Ellis RJ, et al. HIV-associated neurocognitive disorders before and during the era of combination antiretroviral therapy: differences in rates, nature, and predictors. J Neurovirol 2011;17:3-16.

4. Simioni S, Cavassini M, Annoni JM, et al. Cognitive dysfunction in HIV patients despite long-standing suppression of viremia. AIDS 2010;24:1243-50.

5. Ances BM, Clifford DB. HIV-associated neurocognitive disorders and the impact of combination antiretroviral therapies. Curr Neurol Neurosci Rep 2008;8:455-61.

6. Gonzalez-Scarano F, Martin-Garcia J. The neuropathogenesis of AIDS. Nat Rev Immunol 2005;5:69-81.

7. Sattentau QJ. Cell-to-cell spread of retroviruses. Viruses 2010;2:1306-21.

8. Eriksson S, Graf EH, Dahl V, et al. Comparative analysis of measures of viral reservoirs in HIV-1 eradication studies. PLoS Pathog 2013;9:e1003174.

9. Pierson T, McArthur J, Siliciano RF. Reservoirs for HIV-1: mechanisms for viral persistence in the presence of antiviral immune responses and antiretroviral therapy. Annu Rev Immunol 2000;18:665-708

10. Kivela PS, Krol A, Salminen MO, et al. Determinants of late HIV diagnosis among different transmission groups in Finland from 1985 to 2005. HIV Med 2010;11:360-7.

11. Poutiainen E, Elovaara I, Raininko R, et al. Cognitive decline in patients with symptomatic HIV-1 infection. No decline in asymptomatic infection. Acta Neurol Scand 1996;93:421-7.

12. Poutiainen E, Elovaara I, Salonen O, et al. Cognitive performance and brain atrophy in the long term follow-up of HIV-1-infected 
patients [abstract]. 22nd International Neuropsychological Society Mid-Year Conference; 1999.

13. Poutiainen E. Cognitive deficits and emotional disorders in HIV-1 infected individuals. Acta Psychiatr Scand 1995;92:429-35.

14. Poutiainen E, Elovaara I, Raininko R, et al. Cognitive performance in HIV-1 infection: relationship to severity of disease and brain atrophy. Acta Neurol Scand 1993;87:88-94.

15. Poutiainen E, Elovaara I. Subjective complaints of cognitive symptoms are related to psychometric findings of memory deficits in patients with HIV-1 infection. J Int Neuropsychol Soc 1996;2:219-25.

16. Krupp LB, LaRocca NG, Muir-Nash J, et al. The fatigue severity scale. Application to patients with multiple sclerosis and systemic lupus erythematosus. Arch Neurol 1989;46:1121-3.

17. Kurtzke JF. Rating neurologic impairment in multiple sclerosis: an expanded disability status scale (EDSS). Neurology 1983;33:1444-52.

18. Wechsler D. Manual for the Wechsler Memory Scale-Revised. San Antonio, TX: The Psychological Corporation, 1987.

19. Lezak MD, Howieson DB, Loring DW. Neuropsychological Assessment. 4th edn. New York: Oxford University Press, 2004

20. Wechsler D. Wechsler adult intelligence scale. Manual. New York: The Psychological Corporation, 1955.

21. Army Individual Test Battery. Manual of directions and scoring. 1944

22. Stroop JR. Studies in interference in serial verbal reactions. J Exp Psychol 1935;18:643-62.

23. Beck AT, Beck RW. Screening depressed patients in family practice. A rapid technic. Postgrad Med 1972;52:81-5.

24. Fazekas F, Chawluk JB, Alavi A, et al. MR signal abnormalities at 1.5T in Alzheimer's dementia and normal aging. $A J R A m ~ J$ Roentgenol 1987;149:351-6.

25. Chan P, Brew BJ. HIV Associated Neurocognitive Disorders in the Modern Antiviral Treatment Era: Prevalence, Characteristics, Biomarkers, and Effects of Treatment. Curr HIV/AIDS Rep 2014:11:317-24.

26. Brew BJ, Chan P. Update on HIV Dementia and HIV-Associated Neurocognitive Disorders. Curr Neurol Neurosci Rep 2014;14:468.

27. Spudich SS, Nilsson AC, Lollo ND, et al. Cerebrospinal fluid HIV infection and pleocytosis: relation to systemic infection and antiretroviral treatment. BMC Infect Dis 2005;5:98.
28. Kraft-Terry SD, Stothert AR, Buch S, et al. HIV-1 neuroimmunity in the era of antiretroviral therapy. Neurobiol Dis 2010;37:542-8.

29. Elovaara I, Poutiainen E, Lahdevirta J, et al. Zidovudine reduces intrathecal immunoactivation in patients with early human immunodeficiency virus type 1 infection. Arch Neurol 1994;51:943-50.

30. Robertson KR, Robertson WT, Ford S, et al. Highly active antiretroviral therapy improves neurocognitive functioning. J Acquir Immune Defic Syndr 2004;36:562-6.

31. Yilmaz A, Price RW, Gisslen M. Antiretroviral drug treatment of CNS HIV-1 infection. J Antimicrob Chemother 2012;67:299-311.

32. Eden A, Fuchs D, Hagberg L, et al. HIV-1 viral escape in cerebrospinal fluid of subjects on suppressive antiretroviral treatment. J Infect Dis 2010;202:1819-25.

33. Vivithanaporn P, Nelles K, DeBlock L, et al. Hepatitis C virus co-infection increases neurocognitive impairment severity and risk of death in treated HIV/AIDS. J Neurol Sci 2012;312:45-51.

34. Devlin KN, Gongvatana A, Clark US, et al. Neurocognitive effects of HIV, hepatitis C, and substance use history. J Int Neuropsychol Soc 2012;18:68-78.

35. Penzak SR, Chuck SK. Hyperlipidemia associated with HIV protease inhibitor use: pathophysiology, prevalence, risk factors and treatment. Scand J Infect Dis 2000;32:111-23.

36. Muronya W, Sanga E, Talama G, et al. Cardiovascular risk factors in adult Malawians on long-term antiretroviral therapy. Trans $R$ Soc Trop Med Hyg 2011;105:644-9.

37. Benjamin LA, Bryer A, Emsley HC, et al. HIV infection and stroke: current perspectives and future directions. Lancet Neurol 2012;11:878-90.

38. Chow FC, Regan S, Feske S, et al. Comparison of ischemic stroke incidence in HIV-infected and non-HIV-infected patients in a US health care system. J Acquir Immune Defic Syndr 2012;60:351-8.

39. Xu J, Kobayashi S, Yamaguchi S, et al. Gender effects on age-related changes in brain structure. AJNR Am J Neuroradiol 2000;21:112-18.

40. Ge Y, Grossman RI, Babb JS, et al. Age-related total gray matter and white matter changes in normal adult brain. Part I: volumetric MR imaging analysis. AJNR Am J Neuroradiol 2002;23:1327-33 